Cerebrovasc Dis 2008;25:382-384

DOI: $10.1159 / 000120691$

\section{Dural Carotid-Cavernous Fistula: \\ Relationship between Evolution of Clinical Symptoms and Venous Drainage Changes}

Marie Théaudin ${ }^{\mathrm{a}, \mathrm{b}}$, René Chapot ${ }^{\mathrm{c}}$, Katayoun Vahedi ${ }^{\mathrm{a}, \mathrm{b}}$, Marie-Germaine Bousser ${ }^{\mathrm{a}, \mathrm{b}}$

${ }^{a}$ Service de Neurologie, ${ }^{b}$ Centre de Référence pour les Maladies Vasculaires Rares du Système Nerveux Central et de la Rétine, et 'Service de Neuroradiologie, AP-HP, Hôpital Lariboisière, Paris, France

Dural carotid-cavernous fistulae (DCCF) are characterized by abnormal communications between meningeal branches of the internal or external carotid arteries and the cavernous sinus, typically occurring in postmenopausal women [1]. Their underlying pathophysiology is unknown, although a link between DCCF and sinus thrombosis has been suggested $[2,3]$. DCCF present mainly with ophthalmologic signs but, occasionally, they can cause brain infarction or intracranial haemorrhage particularly when there is a leptomeningeal venous drainage [4-7]. Here- in, we report a patient with DCCF draining into leptomeningeal veins who presented with partial seizures and aphasia. After effective percutaneous transvenous embolization of the fistulae, the neurological symptoms worsened due to a cortical brain haemorrhage.

\section{Case Report}

A previously healthy 75-year-old woman had a 1-week episode of severe frontal headache with transient diplopia. Five months later she presented with recurrent diplopia and bilateral conjunctival injection that initially affected the right eye and then extended to the left eye. Ophthalmologic examination showed bilateral episcleral and conjunctival hyperemia, vertical paresis of the left eye and complete ophthalmoplegia and ptosis of the right eye. Visual acuity was normal. Brain CT and MR scans were normal (fig. 1a). Two days after admission, she had three partial motor seizures followed by a right facial palsy and aphasia. Ophthalmologic examination was unchanged. $\mathrm{T}_{2}$-weighted MRI showed a temporo-parietal hyperintense lesion (fig. $1 \mathrm{~b}, \mathrm{c}$ ). There was no sign of venous occlusion in MRI. Conventional angiogram disclosed a right DCCF draining via the coronary sinus into the left cavernous sinus. There were two outflow veins, the left inferior petrosal sinus draining into the internal jugular vein and the left superficial sylvian vein that filled retrogradelly cortical veins in the left temporal and parietal lobes. The right inferior petrosal
Fig. 1. a $\mathrm{T}_{2}$-weighted spin echo in coronal view at admission showing no lesion. b, $\mathbf{c ~}_{2}$-weighted spin echo in coronal view, 2 days later, after the onset of partial seizure showing a left temporo-parietal hyperintense area. d Gradient echo $\mathrm{T}_{2}$ weighted in axial view after endovascular treatment of the DCCF showing a haemorrhage within the left temporo-parietal lesion.
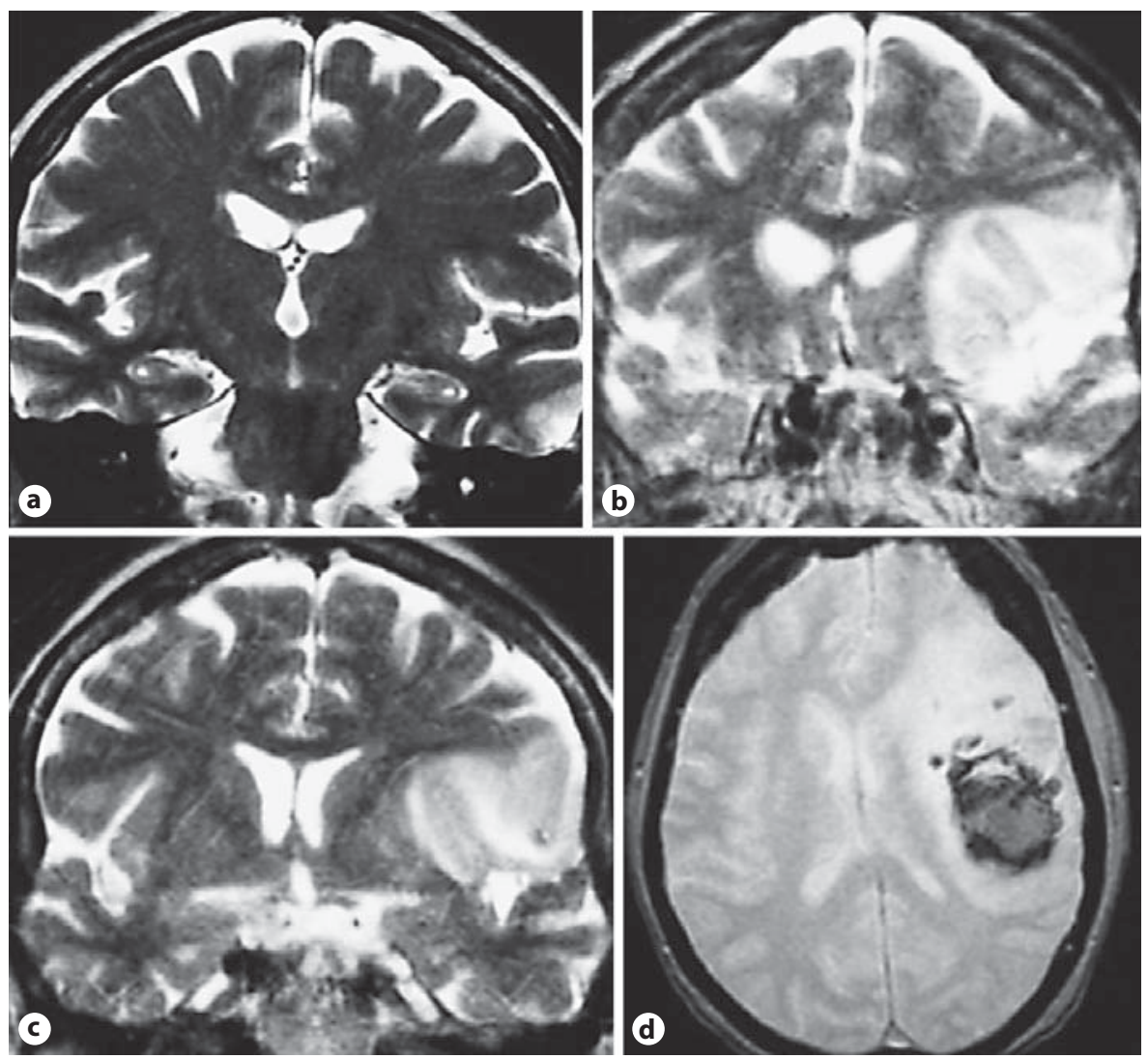


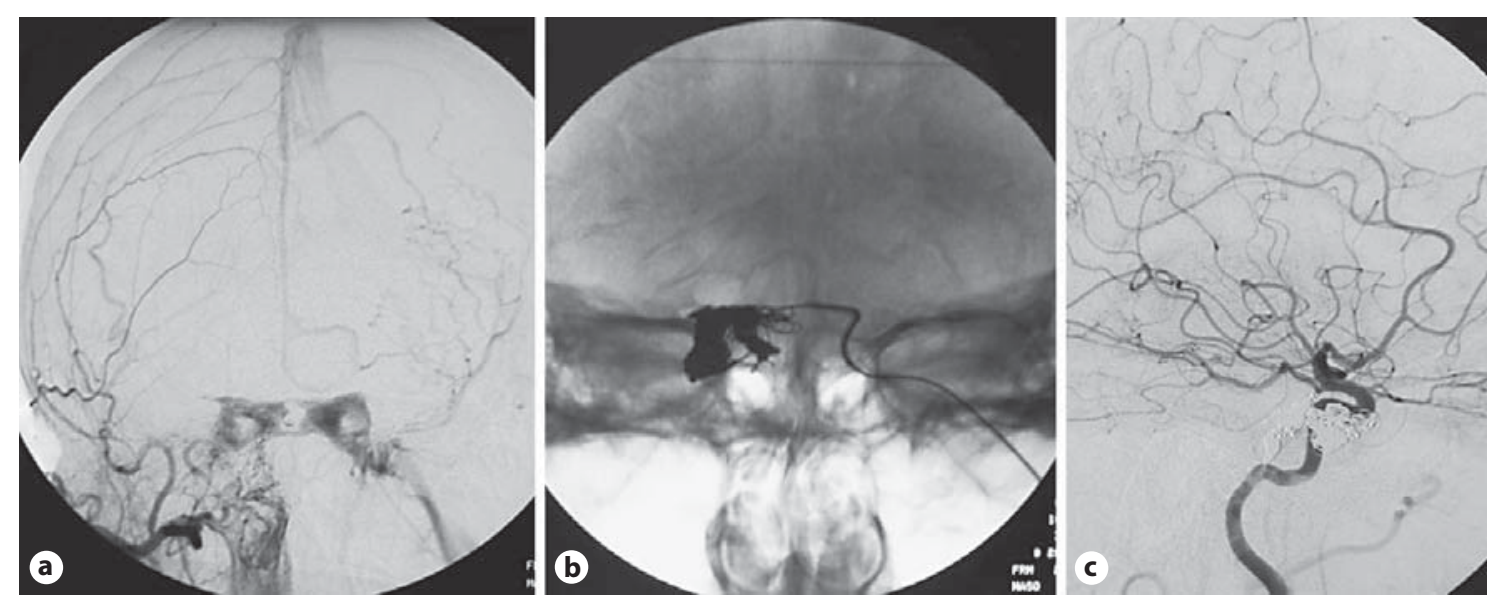

Fig. 2. a Conventional angiogram in the arterial phase discloses a dural fistula of the right cavernous sinus draining via the coronary sinus in the left cavernous sinus with two left outflow veins: the inferior petrosal sinus draining into the internal jugular vein and the superficial sylvian vein refilling retrogradelly cortical veins in the temporo-parietal region. b Embolization is achieved through a venous approach from the left internal jugular vein via the inferior petrosal sinus to the left and then to the right cavernous sinus, which is occluded with coils. c Angiogram at the end of the procedure shows complete occlusion of the dural fistula.

sinus was occluded. Embolization was performed 1 week later under general anaesthesia via a venous approach from the left internal jugular vein to the left cavernous sinus and then to the right one. The right cavernous sinus was occluded with coils, allowing complete occlusion of the dural fistula (fig. 2). Upon awakening, the patient had a right hemiplegia and a worsened aphasia. MRI gradient echo disclosed a haemorrhage within the left temporoparietal lesion (fig. 1d), and gadolinium-enhanced angio-MRI a normal intracranial venous drainage. The ophthalmologic symptoms resolved within a few days and the hemiplegia within 1 month. At 1 year, ophthalmologic examination remained normal, but there was still moderate aphasia.

\section{Discussion}

The present case of DCCF is unusual in that there was a cortical venous drainage with a focal brain lesion, which became hemorrhagic after a technically successful embolization. The focal brain lesion, appearing as a temporo-parietal hypersignal on $\mathrm{T}_{2}$ WI, was most likely a congestive oedema due to the reversal of blood flow in its draining vein, i.e. the superficial sylvian vein [8]. The chronology of symptoms is indeed highly suggestive of successive changes in the venous outflow of the DCCF. The patient first had a right eye ophthalmoplegia suggesting a retrograde flow in the right ophthalmic vein, and later similar symptoms on the left, suggesting a venous outflow in the left ophthalmic vein. Brain MRI performed at that time showed no parenchymal brain lesion. She then presented seizures and aphasia with appearing temporo-parietal lesion on $\mathrm{T}_{2}$-WI. Angiography performed at that time showed drainage of the fistula into the superficial sylvian vein with bilateral ophthalmic vein thrombosis. It is therefore likely that the outflow of the fistula changed from the right to the left ophthalmic vein and finally to the superficial sylvian vein.

The patient developed a haemorrhage within the initial temporo-parietal lesion during or shortly after a technically successful endovascular treatment of the DCCF. Although a hyperperfusion syndrome cannot be completely ruled out [9], a more likely hypothesis would be a temporary increase in blood flow in the left sylvian vein during embolization with a subsequent worsening of the congestive oedema and the occurrence of a venous haemorrhage. Indeed, since the fistula drained simultaneously in the contralateral inferior petrosal sinus and in the superficial sylvian vein, it is possible that the catheter within the inferior petrosal sinus, which was used to access the fistula, may have temporarily reduced the flow in the sinus, thereby increasing the flow in the left sylvian vein. To conclude, in case of unilateral occlusion of the inferior petrosal sinus, a contralateral flow reduction might cause a dangerous drainage impairment, especially in the most distant venous drainage regions. As a result, although such a phenomenon has not yet been described and is still hypothetical, it may be preferable in a similar situation to re-canalize the occluded inferior petrosal sinus to access the cavernous sinus rather than to navigate through the patent petrosal sinus draining the fistula.

\section{References}

$\checkmark 1$ Meyers PM, Halbach VV, Dowd CF, Lempert TE, Malek AM, Phatouros CC, Lefler JE, Higashida RT: Dural carotid cavernous fistula: definitive endovascular management and long-term follow-up. Am J Ophthalmol 2002;134:85-92.

2 Chaudhary MY, Sachdev VP, Cho SH, Weitzner I Jr, Puljic S, Huang YP: Dural arteriovenous malformation of the major venous sinuses: an acquired lesion. AJNR Am J Neuroradiol 1982;3:13-19. 
3 Brainin M, Samec P: Venous hemodynamics of arteriovenous meningeal fistulas in the posterior cranial fossa. Neuroradiology 1983;25: 161-169.

4 Cognard C, Gobin YP, Pierot L, Bailly AL, Houdart E, Casasco A, Chiras J, Merland JJ: Cerebral dural arteriovenous fistulas: clinical and angiographic correlation with a revised classification of venous drainage. Radiology 1995;194:671-680.

5 Vinuela F, Fox AJ, Debrun GM, Peerless SJ, Drake CG: Spontaneous carotid-cavernous fistulas: clinical, radiological, and therapeutic considerations. Experience with 20 cases. J Neurosurg 1984;60:976984.

6 Gobin Y, Duckwiler G, Guglielmi G: Endovascular techniques in the treatment of carotid cavernous fistulas; in Eisenberg MB, Al-Mefty O (eds): The Cavernous Sinus. Philadelphia, Lippincott Williams \& Wilkins, 2000, pp 209-225.
-7 Halbach VV, Higashida RT, Hieshima GB, Reicher M, Norman D, Newton TH: Dural fistulas involving the cavernous sinus: results of treatment in 30 patients. Radiology 1987;163:437-442.

8 Meder JF, Chiras J, Roland J, Guinet P, Bracard S, Bargy F: Venous territories of the brain. J Neuroradiol 1994;21:118-133.

9 Willinsky R, Terbrugge K, Montanera W, Mikulis D, Wallace MC: Venous congestion: an MR finding in dural arteriovenous malformations with cortical venous drainage. AJNR Am J Neuroradiol 1994;15:15011507.

Marie Théaudin, MD

AP-HP, Hôpital Lariboisière, Service de Neurologie

2, rue Ambroise Paré, FR-75475 Paris Cedex 10 (France)

Tel. +331 4521 2403, Fax +3314521 2853

E-Mailmtheau@yahoo.fr 